\title{
The Frequency and Distribution of Idiopathic Osteosclerosis of the Jaw
}

\author{
Yildiray Sisman ${ }^{a}$ \\ Elif Tarim Ertas ${ }^{b}$ \\ Huseyin Ertas ${ }^{c}$ \\ Ahmet Ercan Sekerci ${ }^{d}$
}

\section{ABSTRACT}

Objectives: To determine the prevalence of idiopathic osteosclerosis (IO) in the jaw by radiographic evaluation and to investigate the relationship between the findings in relation to age, gender, and localization.

Methods: The study included 2,211 panoramic radiographs obtained from the patients 1915 men and 1,296 women) whose ages ranged from 10-77 and who visited the Department of Oral Diagnosis and Radiology in the Faculty of Dentistry, Erciyes University between 2008 and 2009.

Results: Of 2,211 patients, 135 patients (6.1\%) had I0. The prevalence obtained in our study was in the range reported in the literature. 10 was detected more often in mandible rather than the maxilla. In addition, mandibular molar localization was the most common localization, and most of the lesions were associated with root apices.

Conclusions: In view of the findings, 10 can be defined as developmental variations of normal bony architecture, which are unrelated to local stimuli. The lesions can arise at any age, any location with no sex predilection, and 10 usually requires no treatment other than diagnosis. Because all these lesions were located in the jaw and could only is detected in panoramic evaluations, this indicates the importance of careful diagnostic evaluation of radiographies in dental examinations. (Eur J Dent 2011;5:409-414)

Key words: Idiopathic osteosclerosis; Mandible; Maxilla; Panoramic radiograph.

a Associate Professor and Chair, Department of Oral and Maxillofacial Radiology, Faculty of Dentistry, Erciyes University, Kayseri, Turkey.

b Assistant Professor, Department of Oral and Maxillofacial Radiology, Faculty of Dentistry, Izmir Katip Celebi University, Izmir, Turkey.

Assistant Professor, Department of Endodontics, Faculty of Dentistry, Izmir Katip Celebi University, Izmir, Turkey.

d Research Assistant, Department of Oral and Maxillofacial Radiology, Faculty of Dentistry,

Erciyes University, Kayseri, Turkey.

- Corresponding author: Ahmet Ercan Sekerci Department of Oral and Maxillofacial Radiology, Faculty of Dentistry, Erciyes University, 38039, Kayseri, Turkey. Phone: +90 352437 4901/29227 Fax: +90 3524380657 E-mail: aercansekerciahotmail.com

\section{INTRODUCTION}

Idiopathic osteosclerosis (IO) is an area of increased bone production in the jaw and generally appears to be round, elliptical, or irregular and radiopaque in shape..$^{1-3}$ According to the literature, although this disorder is sometimes described as a dense bone island, bone scar, focal periapical osteopetrosis, or enostosis, ${ }^{3}$ IO is often preferred because of its unknown origin. ${ }^{4-6}$ These lesions may be accepted as developmental intraosseous anatomic variations ${ }^{7}$ and should be classified separately from the cases resulting from inflammatory origin or systemic disease. ${ }^{4-6}$ These asymptomatic lesions are generally discovered as incidental findings on radiographs taken for other reasons. $^{7}$ 
On radiographic evaluation, 10 may be detected in various sizes, ranging from 2 or $3 \mathrm{~mm}$ to 1 or $2 \mathrm{~cm}$ in diameter, ${ }^{2,3,8-10}$ or the lesions may be very large, almost the entire height of the body of the mandible. ${ }^{11,12}$ They may occur at root apexes, between the roots, or in a separate location away from the teeth, primarily in the premolar/molar region and with a predilection for the mandibular arc. 2,3,5,13,14

The purpose of this study was to determine the prevalence and distribution of the 10 in the jaws of the patients attending our facility by examining the panoramic radiographs the patient records, and to investigate the relationship of the findings to the age and gender in the population of the Cappadocia region.

\section{MATERIALS AND METHODS}

A total of 2,211 dental patients admitted to the Faculty of Dentistry, Erciyes University, in the Cappadocia region of Turkey participated in the study, which was based on the panoramic radiographs (PRs) of the patients taken during routine dental examination, and all the radiographs were examined by YS in terms of the presence of 10 on a standard light-box under normal room lighting. All the PRs were obtained with an Orthopantomograph OP 100 (Orthopantomography® OP100, Tuusula, Finland). The PRs were processed according to the manufacturer's recommendations in an automatic film processor. The radiographs that displayed the jaws, without asymmetry, distortion, or error in patient positioning or exposure processing were included in the study.

For the diagnosis, 10 was defined as the symptomless, radiopaque areas that are often elliptical or round in shape and vary in size from a minimum of $3 \mathrm{~mm}$ to more than $2 \mathrm{~cm}$. The patients who had a questionable 10 and who met the following criteria were excluded from this study. $2,8,15$

- Radiopacities directly associated with deep caries or large restorations;

- The characteristics of the lesion were mixed with radiopaque-radiolucent areas in the form of periapical cemental dysplasia and other benign fibro-osseous lesions or an odontome;

- The remnants of deciduous or permanent teeth were clearly identifiable;

- The radiopacities were interpreted as a tori or exostoses, salivary calculus, tonsolith, or calcified lymph node;
- There is an increased thickening of the lamina dura around teeth with marked malposition or which were serving as abutments for fixed bridges or partial dentures;

- Solitary radiopacities in edentulous regions.

Radiopaque areas that were depicted as 10 were classified as follows ${ }^{2}$ (Figures 1A-E):

1. Interradicular: if the sclerotic area was confined between the roots and interrelated with the adjacent teeths' lamina dura;

2. Interradicular and separate: if the sclerotic area was confined between the roots and not interrelated with the adjacent teeths' lamina dura;

3. Apical and interradicular: if the radiopacities were at the apices and showed significant extension between the roots;

4. Apical: if the lesions were located around the apices of the roots;

5. Separate: if the masses were located apically and clearly separated from the teeth and lamina dura.

Statistical analysis

For each patient, demographic data was recorded in order to investigate the relationship between the findings and age, gender, and localization. The observed results were analyzed with SPSS 16.0 (Statistical Package for Social Science Inc., Chicago, Illinois, USA). Data was obtained using the chi-square test, and the results were considered to have a significant difference if the significance level was less than 05 .

\section{RESULTS}

Osteosclerosis was identified in 135 of the 2,211 patients, for an overall prevalence of $6.1 \%$ of patients. In these 135 patients, a total of 153 foci were identified. One hundred twenty-three patients had 110 , nine patients had $210 \mathrm{~s}$, two patients had $310 \mathrm{~s}$, and one patient had four foci of IOs. There is a statistically significant difference between the rates of occurrence in the jaws $(P<.001)$; the vast majority occurred in the mandible, and only 19 foci were detected in maxilla and 134 in the mandible.

The patient population as a whole consisted of approximately $59 \%$ females and $41 \%$ males. The prevalence of 10 among females was $5.9 \%$ (77 females) and 6.3\% (58 males) among males. There was no statistically significant difference in the 
prevalence of 10 between the males and females $(P=.768)$.

The ages of the study group ranged from 10 to 77 years with a median of 26 years. Most lesions were found in patients between the ages of 21 and 30 . No significant difference in prevalence of 10 was found among age groups (Table 1) $(P=.3654)$.
In the maxilla, the most common location of 10 was the anterior area whereas in the mandible, most lesions were detected in the molar region. Table 2 shows the distribution of 10 when examining the jaws and localization.

Most of the lesions of 10 , approximately $51.6 \%$, were associated with the root apices. Separate lo-

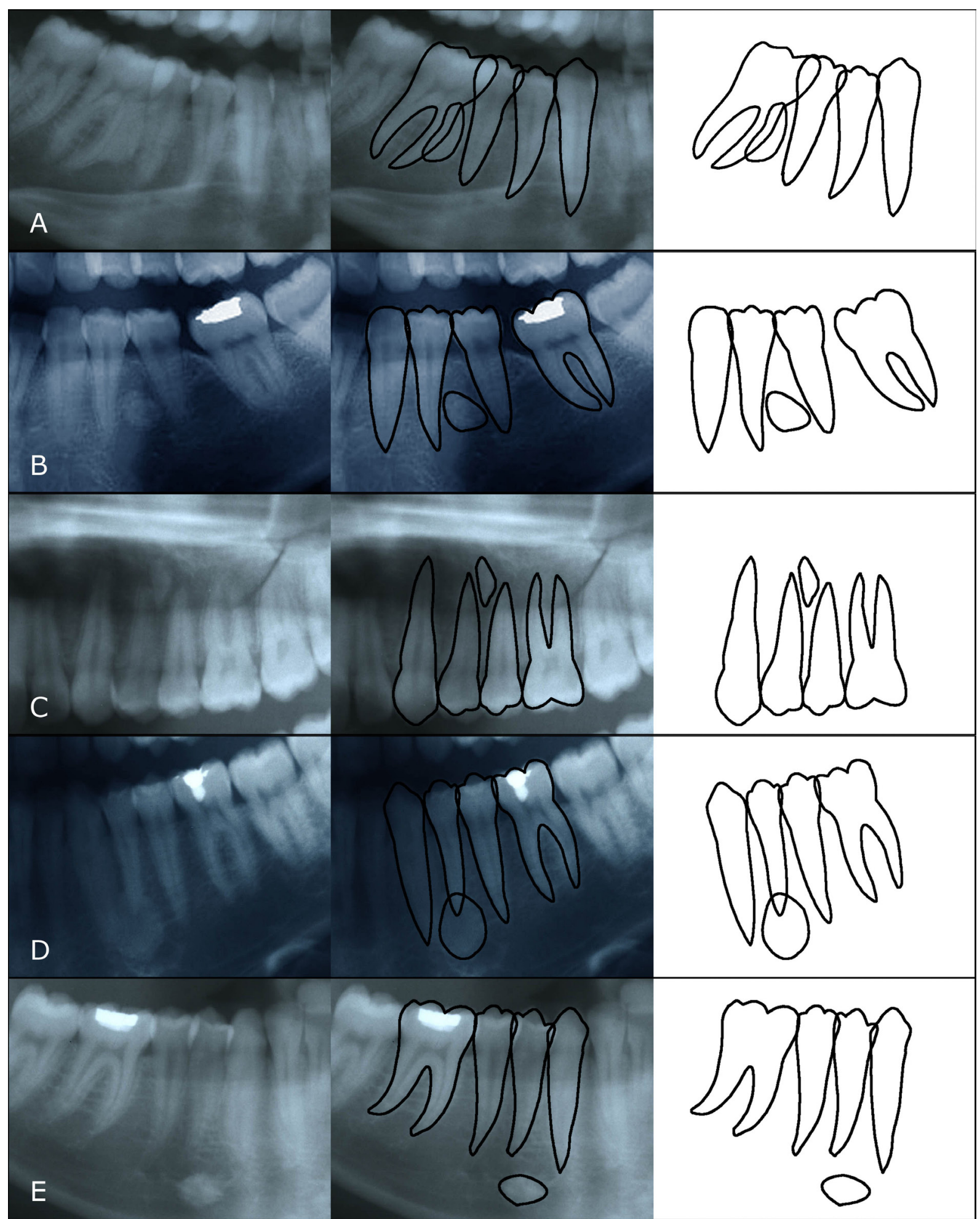

Figure 1. Radiographic appearance of the osteosclerotic lesions which were detected in A; interradicular, B; interradicular and separate, C; apical interradicular, D; apical, E; separate localization. 
calization in which the lesions were apical to and clearly separated from the teeth and lamina dura was the second most common localization with $22.9 \%$ prevalence. Seventeen percent of the lesions were detected at the apices and showed extension to the interradicular areas; $6.5 \%$ were in interradicular areas; and $2 \%$ were detected in interradicular and separate localizations (Table 2).

\section{DISCUSSION}

The frequency of 10 observed in this study was $6.1 \%$, the same as the prevalence found by Yonetsu et al. ${ }^{4}$ In the literature, the prevalence varies from $4 \%$ to $31 \%$, and our findings fall within this range. ${ }^{2,8,16,17}$ One of the reasons for the variation in the studies is the different definitions of osteosclerosis. ${ }^{4}$ Some researchers included radiopacities that are related to traumatic occlusion or pulpal inflammation, while others excluded these kinds of lesions from their study. ${ }^{2,4}$ In our study, solitary radiopacities in edentulous regions were not included, and asymptomatic radiopaque masses within the jaws which had no certain relationship to any known sources of hard tissue production were accepted as idiopathic osteosclerosis. ${ }^{2}$ Another reason may be the choice of radiography. In some studies, periapical radiographs were examined ${ }^{1,2}$ whereas in some others, panoramic radiographs were used as the tool of investigation. ${ }^{3,4}$ In our study, we also preferred using panoramic radiographs in order to detect larger areas in jaws.

Some researchers reported a female predilection for the incidence of $10^{5}$ while others showed no significant difference in prevalence between males and females as in our study. $4,8,15,17$ The ages of our study group were ranged from 10 to 77 and there was no significant difference in prevalence of 10 among age groups similar to results of $Y_{0}$ netsu et $\mathrm{al}^{4}$ and Kawai et al. ${ }^{18}$

Table 1. Age distribution of 10 present patients of the study population

\begin{tabular}{lccc}
\hline Age group & All patients & I0 present & Percentage \\
\hline $10-19$ & 699 & 43 & $6.2 \%$ \\
$20-29$ & 511 & 43 & $8.4 \%$ \\
$30-39$ & 334 & 22 & $6.6 \%$ \\
\hline $40-49$ & 274 & 18 & $6.6 \%$ \\
\hline $50-59$ & 181 & 7 & $3.9 \%$ \\
$60-69$ & 62 & 2 & $3.2 \%$ \\
$70-$ & 14 & 0 & $.0 \%$ \\
\hline Total & 2075 & 135 & $6.1 \%$ \\
\hline
\end{tabular}

Table 2. Location of lesions and relation to teeth.

\begin{tabular}{|c|c|c|c|c|c|c|}
\hline & Interradicular & $\begin{array}{l}\text { Interradicular } \\
\text { and Separate }\end{array}$ & $\begin{array}{c}\text { Apical and } \\
\text { Interradicular }\end{array}$ & Apical & Separate & Total \\
\hline \multicolumn{7}{|l|}{ Maxilla } \\
\hline Anterior & 0 & 0 & 2 & 8 & 1 & $11 / 153(7.2 \%)$ \\
\hline Canin & 0 & 0 & 0 & 0 & 0 & $0 / 153(.0 \%)$ \\
\hline Canin-premolar & 0 & 0 & 1 & 0 & 0 & 1/153 (0.7\%) \\
\hline Premolar & 1 & 0 & 0 & 1 & 2 & $4 / 153(2.6 \%)$ \\
\hline Premolar-molar & 0 & 0 & 0 & 0 & 0 & $0 / 153(.0 \%)$ \\
\hline Molar & 0 & 0 & 0 & 3 & 0 & $3 / 153(2.0 \%)$ \\
\hline \multicolumn{7}{|l|}{ Mandible } \\
\hline Anterior & 1 & 0 & 2 & 5 & 3 & $11 / 153(7.2 \%)$ \\
\hline Canin & 0 & 0 & 1 & 14 & 2 & $17 / 153(11.1 \%)$ \\
\hline Canin-premolar & 1 & 0 & 3 & 0 & 3 & $7 / 153$ (4.6\%) \\
\hline Premolar & 2 & 1 & 5 & 16 & 15 & $39 / 153(25.5 \%)$ \\
\hline Premolar-molar & 2 & 2 & 4 & 0 & 3 & $11 / 153(7.2 \%)$ \\
\hline Molar & 3 & 0 & 8 & 32 & 6 & 49/153 (32.\%) \\
\hline Total & $10 / 153(6.5 \%)$ & $3 / 153(2 \%)$ & $26 / 153(17 \%)$ & $79 / 153(51.6 \%)$ & $35 / 153(22.9 \%)$ & \\
\hline
\end{tabular}


Although in their studies Geist and Katz ${ }^{2}$ and Sun et $\mathrm{al}^{18}$ reported the highest occurrence in the premolar region, the results of this study support the previous findings, which indicated the most common location of 10 is in the first molar region of the mandible. $4,5,13,18$

In our study, most of the lesions of 10 were found to be associated with the root apices. Traumatic occlusion and traumatic movement of teeth is known to be a possible explanation for $10 .{ }^{2} \mathrm{Al}-$ though the radiopacities around teeth that showed malposition or seemed to be subject to abnormal occlusal forces were excluded from our study group, slight imbalances in occlusion that provide enough vibratory stimulus to provoke bone formation might escape radiographic detection, and this might explain why the highest predilection of the lesions was associated with the root apices.

In some studies, 10 was reported to be an anatomic variation. 2,19,20 In our study, separate localizations, where the lesions were apical to and clearly separated from the teeth and lamina dura, was the second most common localization with $22.9 \%$ prevalence. Because the lesions were clearly separated from the teeth, and there were no residual tooth fragments or the stimulatory effects of excessive occlusion would not be a factor in this localization, may support the possibility that IO may be a developmental anatomic variation.

\section{CONCLUSIONS}

In light of these findings, we can define 10 as developmental variations of normal bony architecture unrelated to local stimuli. The lesions can arise at any age, at any location, and with no sex predilection, and 10 usually requires no treatment other than diagnosis by recognition. ${ }^{7}$ Generally, the lesions are likely to remain for years, and surgical intervention is not recommended. To be sure that the clinical diagnosis is correct, periodic follow-up of the lesions is necessary. Although it is rare, if resorption occurs in the associated root over time, endodontic treatment or extraction of the affected tooth may be necessary. ${ }^{7}$

\section{REFERENCES}

1. Halse A, Molven 0. Idiopathic osteosclerosis of the jaws followed through a period of 20-27 years. Int Endod J 2002;35:747-751.
2. Geist JR, Katz JO. The frequency and distribution of idiopathic osteosclerosis. Oral Surg Oral Med Oral Pathol 1990;69:388-393

3. Petrikowski CG, Peters E. Longitudinal radiographic assessment of dense bone islands of the jaws. Oral Surg Oral Med Oral Pathol Oral Radiol Endod 1997;83:627-634.

4. Yonetsu K, Yuasa K, Kanda S. Idiopathic osteosclerosis of the jaws: panoramic radiographic and computed tomographic findings. Oral Surg Oral Med Oral Pathol Oral Radiol Endod 1997;83:517-521.

5. McDonnell D. Dense bone island: a review of 107 patients. Oral Surg Oral Med Oral Pathol 1993;76:124-128.

6. Gibilisco JA. Stafne's oral radiographic diagnosis. In: Gibilisco JA (ed). Philadelphia: WB Saunders, 1985:142-146.

7. Bsoul SA, Alborz S, Terezhalmy GT, Moore WS. Idiopathic osteosclerosis lenostosis, dense bone silands, focal periapical osteopetrosis). Quintessence Int 2004;35:590-591.

8. Austin BW, Moule AJ. A comparative study of the prevalence of mandibular osteosclerosis in patients of Asiatic and Caucasian origin. Aust Dent J 1984;29:36-43.

9. Langlais RP, Langland OE, Nortje CJ. Diagnostic imaging of the jaws. In: Langlais RP, Langland OE, Nortje CJ. (eds). Baltimore: Williams and Wilkins, 1995:530-532.

10. White SC, Pharoah MJ. Bening Tumors of the Jaws. In: White SC, Pharoah MJ. (eds). Oral radiology: principles and interpretation. 4th ed. St Louis: CV Mosby, 2000:384-386.

11. MacDonald-Jankowski DS. Idiopathic osteosclerosis in the jaws of Britons and of the Hong Kong Chinese: radiology and systematic review. Dentomaxillofac Radiol 1999;28:357363.

12. Kawai T, Murakami S, Kishino M, Sakuda M. Gigantic dense bone island of the jaw. Oral Surg Oral Med Oral Pathol Oral Radiol Endod 1996;82:108-115.

13. Eversole LR, Stone CE, Strub D. Focal sclerosing osteomyelitis/ focal periapical osteopetrosis: radiographic patterns. Oral Surg Oral Med Oral Pathol 1984;58:456-460.

14. Kawal T, Hirakuma H, Murakami S, Fuchihata H. Radiographic investigation of idiopathic osteosclerosis of the jaws in Japanese dental outpatients. Oral Surg Oral Med Oral Pathol 1992;74:237-242.

15. Wood NK, Goaz. Differential diagnosis of oral lesions. In: Wood NK, Goaz PW. (eds.) St Lous: CV Mosby, 1980:566567.

16. Boyne PJ. Incidence of osteosclerotic areas in the mandible and maxilla. J Oral Surg Anesth Hosp Dent 1960;18:486491.

17. Farman AG, Joubert JJ DeV, Nortje CJ. Focal osteosclerosis and apical periodontal pathoses in 'European' and Cape Coloured dental outpatients. Int J Oral Surg 1978;7:549557. 
18. Kawai T, Hirakuma H, Murakami S, Fuchihata H. Radiographic investigation of idiopathic osteosclerosis of the jaws in Japanese dental outpatients. Oral Surg Oral Med Oral Pathol 1992;74:237-242.

19. Eselman JC. A roentgenographic investigation of enostosis. Oral Surg Oral Med Oral Pathol 1961;14:1331-1338.

20. Fireman SM. Osteosclerotic lesions of the jaws. Oral Health 1976;66:27-29. 